\title{
Valoração das práticas de ensino, pesquisa e extensão entre concluintes de Odontologia
}

\author{
Amanda Borato*; Marcos Vinícius de Sousa Pereira*; Danielle Bordin**; Alessandra de Souza \\ Martins**; Cristina Berger Fadel*** $^{* *}$
}

* Estudante de graduação em Odontologia, Universidade Estadual de Ponta Grossa

** Doutora, Professora colaboradora, Universidade Estadual de Ponta Grossa

*** Doutora, Docente da Universidade Estadual de Ponta Grossa

Recebido em 11/04/2017. Aprovado em 03/07/2017.

\begin{abstract}
RESUMO
Frente à importância da complementaridade e interdependência entre os pilares da educação superior, o objetivo deste estudo é conhecer o valor atribuído às práticas de ensino, pesquisa e extensão por acadêmicos concluintes de Odontologia. Realizou-se um estudo exploratório descritivo, com a utilização de metodologia quali-quantitativa, desenvolvido junto à totalidade de formandos do curso de Odontologia de uma instituição pública de ensino superior (ano base: 2016) $(n=54)$. A apreensão das informações de interesse para esse estudo se deu por meio de uma questão estruturada e de três questões norteadoras abertas. Os resultados quantitativos foram tabulados por meio de estatísticas descritivas e os dados qualitativos foram tratados de acordo com a técnica de análise do Discurso do Sujeito Coletivo. Referente à participação dos alunos em atividades complementares institucionais, $73,1 \%$ afirmou ter participado de pesquisa científica, $63,5 \%$ de atividades de extensão, e 80,8\% de atividades de monitoria; sendo que somente 34,6\% formandos afirmaram ter vivenciado as três atividades analisadas. Das informações obtidas foram extraídos cinco temas e dezessete ideias centrais. As ideias mais compartilhadas entre os pesquisados, em relação a cada tema extraído, apontam para uma maior valorização do ensino, quando comparado a extensão e a pesquisa; para o entendimento de que a sua instituição de ensino superior valoriza a pesquisa de forma ampliada e para a crença de que o ensino, a pesquisa e a extensão são eixos institucionais conexos na instituição. Os resultados alcançados evidenciam a necessidade do aprimoramento das práticas de construção e compartilhamento do conhecimento na instituição analisada.
\end{abstract}

Descritores: Odontologia. Educação Superior. Pesquisa Qualitativa.

\section{INTRODUÇÃO}

O propósito da construção do conhecimento no sistema de ensino superior brasileiro deve ser pensado considerando-se a diversidade de sua estrutura e organização, além dos fatores econômicos, sociais e culturais. Contudo, de forma igualitária e fruto do resultado do esforço do governo em disciplinar sobre um modelo de produção de saber científico, as universidades devem obedecer ao princípio da 
indissociabilidade entre o ensino, a pesquisa e a extensão ${ }^{1,2}$. Esse dispositivo triplo possui caráter fundamental, não somente na geração de conhecimentos técnicos e científicos, como na formação de recursos humanos e no desenvolvimento social.

No entanto, mesmo que presente na constituição brasileira desde $1988^{1}$, a consolidação do princípio da indissociabilidade ainda é um desafio atual. Especificamente para os cursos de Odontologia no Brasil, em fevereiro de 2002, foram aprovadas as Diretrizes Curriculares Nacionais (DCN), as quais passaram a fundamentar o planejamento e a orientação dos currículos dos cursos de graduação $^{3}$. Para as DCN, a inclusão de cenários de aprendizagem que compreendam os espaços públicos de atenção básica, como o Sistema Único de Saúde (SUS), é fundamental para a qualidade da formação profissional ${ }^{3}$, capacitando o acadêmico para uma ampla comunicação com a sociedade e para um perfil crítico, reflexivo e humano.

A aprendizagem no Brasil sempre apresentou como agente basilar a figura do professor, em um modelo nominado tradicional ou condutista ${ }^{4}$, com foco na transmissão do conhecimento ou do saber ${ }^{5}$. Autores afirmam que esse é ainda o modelo pedagógico vigente em grande parte das universidades brasileiras ${ }^{6-10}$, em detrimento ao modelo construtivista, baseado na construção do conhecimento por meio do esforço do pensar, do abrir espaços para a reflexão, do aprender a aprender, aprender a estudar, do estímulo à curiosidade intelectual e ao questionamento à dúvida ${ }^{11}$. Desta forma, modernamente, a construção do saber induz que o conhecimento seja não apenas sistematizado e gerenciado por um professor, mas constantemente estimulado e reelaborado, promovendo novos espaços de práticas e de reflexão. Para tanto, acredita-se na formação profissional mediante um processo de ensino e aprendizagem de habilidades e competências técnicas; de competências científicas com disponibilização de métodos e conteúdos de conhecimento; e de competência cidadã, pelo estímulo do estudante para a tomada de consciência de sua existência histórica e social ${ }^{12,13}$.

Mediante as perspectivas com o uso dos meios atuais de produção e compartilhamento do conhecimento em uma universidade pública brasileira, desenvolveu-se este estudo. O objetivo principal é conhecer o valor atribuído às práticas de ensino, pesquisa e extensão vivenciadas por acadêmicos concluintes de Odontologia, durante a graduação universitária.

\section{DELINEAMENTO E CONSTRUÇÃO DO CORPUS}

Assumiu-se que, apesar do princípio da indissociabilidade entre ensino, pesquisa e extensão ter sido configurado no cenário da educação superior brasileira há quase trinta anos, ainda é um tema complexo e discutido por vários autores. Além disso, considerou-se que a formação do profissional da Área da Saúde vem sendo problematizada à luz do SUS, a qual exige que os profissionais se tornem mais comprometidos com a igualdade na saúde, ampliando a dimensão de cuidado na prática profissional.

Ainda, que a matriz curricular estabelecida pela Instituição de Ensino Superior (IES), para o curso de graduação investigado, auxilia na explicação das respostas sobre a coexistência entre as atividades de ensino, pesquisa e extensão como acesso único a aprendizagem. Por mais que haja avanço na visibilidade das diferentes atividades percebida pelos alunos, percebe-se que não há reflexão nas narrativas quanto ao fazer pedagógico ou quanto às experiências formativas continuamente repensadas ou reconstruídas. 
Cada resposta obtida vincula e comunica uma fala, à lógica e ao pensamento de cada aluno, e é notada obedecendo a uma estrutura que atribui sentido às experiências por eles vivenciadas. Tem-se, então, subjetivamente a exposição de um acontecimento ou de uma série de acontecimentos, expressados por meio de palavras. Logo, as respostas obtidas são a interpretação dada pelos alunos sobre a qualidade da ordenação, que permita indicação das possibilidades de integração, de suas práticas acadêmicas.

Nesta pesquisa, as causas associadas ao não cumprimento do princípio da indissociabilidade foram discutidas. $\mathrm{O}$ estudo comprova o pressuposto de que todas as IES tentam, de alguma forma, chegar à materialização da indissociabilidade, buscando determinar novas relações e papéis para uma tomada assertiva de decisões.

\section{METODOLOGIA}

O presente estudo obedeceu aos preceitos estabelecidos pela Resolução $n^{\circ}$ 466/2012 do Ministério da Saúde e foi submetido e aprovado por Comitê de Ética em Pesquisa da Universidade Estadual de Ponta Grossa-PR $\left(\mathrm{CAAE} \quad \mathrm{n}^{\mathrm{o}} \quad\right.$ 53396016.9.0000.0105), sendo respeitados os aspectos relacionados com o anonimato total do entrevistado, sua privacidade e autonomia para aceitar ou não a participação no estudo. Todos os participantes assinaram termo de consentimento livre e esclarecido.

Adotou-se o modelo de estudo exploratório descritivo, com abordagem quali-quantitativa e utilização da técnica do Discurso do Sujeito Coletivo (DSC). A pesquisa foi planejada para a totalidade de acadêmicos concluintes do curso de Odontologia de uma universidade pública do sul do Brasil $(n=54)$. Foram eleitos os concluintes, considerando o seu prévio contato com todas as atividades obrigatórias e complementares do curso.

O questionário foi respondido por 52 acadêmicos, com média etária de 22 anos, sendo a maioria mulheres. A perda de indivíduos se deu pela ausência de acadêmicos no momento da coleta de informações $(n=2)$. O único critério de inclusão foi o indivíduo estar cursando o último ano letivo do referido curso de graduação. $\mathrm{O}$ ano base para a consulta foi 2016 .

Quanto às atividades curriculares obrigatórias, os investigados possuem no mínimo 5.164 horas para integralização da carga horária do curso, sendo 34 horas destinadas para o desenvolvimento do trabalho de conclusão de curso (TCC). Deste total, duzentas horas mínimas são destinadas a atividades complementares institucionais, podendo ser divididas em atividades de extensão, de pesquisa e iniciação científica, e em monitoria.

Dentre as atividades curriculares, além de aulas teóricas presenciais e do TCC, o aluno vivencia atenção clínica em saúde bucal à comunidade externa nas dependências intra e extramuros da instituição e ainda estágio supervisionado no SUS. Em relação às atividades complementares, o referido curso conta, atualmente, com sete projetos de extensão institucionalizados, sendo três de entrada voluntária e quatro financiados por meio de bolsas de apoio financeiro; programas anuais de apoio à iniciação científica com fomento externo e interno; e participação em programas de monitoria acadêmica, com ou sem auxílio financeiro. A inclusão dos acadêmicos nestas iniciativas ocorre por meio de editais próprios.

A apreensão das percepções sobre o valor atribuído às práticas de ensino, pesquisa e extensão foi coletada por meio de um questionário inédito, elaborado especialmente para fins da pesquisa, aplicado coletivamente em sala de aula e em momento considerado propício pelos sujeitos. A pergunta inicial, estruturada e 
quantitativa, fazia referência ao número e qualidade das atividades complementares vivenciadas durante a graduação. As demais questões, abertas e qualitativas, foram de resposta livre, a seguir transcritas. Não houve restrição de tempo para o preenchimento do questionário.

- Considerando o ensino, a pesquisa e a extensão, fale sobre o que teve maior importância em sua formação acadêmica.

- Considerando o ensino, a pesquisa e a extensão, fale sobre o que tem maior importância para a sua universidade.

- Para você, existe uma correlação forte entre as atividades de ensino, pesquisa e extensão de sua universidade?

Como referencial metodológico para a tabulação das informações qualitativas foi adotada a teoria das Representações Sociais, composta por elementos como crenças e opiniões, os quais são organizados a fim de expressar a realidade ${ }^{14}$, e a análise e apresentação dos resultados teve por base a técnica do DSC, proposta Lefèvre e Lefèvre $(2003)^{15}$. Este consiste na reunião, em um só discurso-síntese, de vários discursos individuais emitidos como resposta a uma mesma questão de pesquisa, por sujeitos social e institucionalmente equivalentes ou que fazem parte de uma mesma cultura organizacional e de um grupo social homogêneo. Ou seja, busca unir o conteúdo das respostas obtidas, organizando-as e deixando evidente a representação social no pensamento coletivo. O método DSC busca então a criação de um vínculo entre senso comum e conhecimento científico partindo da reconstituição de um pensamento coletivo, fundamentado nas representações sociais.

A questão fechada foi tabulada e deu origem aos gráficos 1 e 2 . Os resultados oriundos de cada questão aberta norteadora foram digitados em planilha do Microsoft Office Excel versão 2010 e, após leitura exaustiva, foram categorizados: a) identificação das expressõeschave (E-Ch) de conteúdo similar, ou seja, os trechos de cada depoimento que melhor descrevem o seu conteúdo; b) identificação das ideias centrais (IC), referente aos conjuntos de respostas de diferentes indivíduos que apresentam sentido semelhante ou complementar, c) formulação de uma síntese única originária dos discursos (DSCs), onde as expressões-chaves aparecerem organizadas segundo ideias centrais de significados semelhantes, sendo o pensamento de um grupo ou coletividade representado como individual. Para melhor visualização dos resultados obtidos e apreensão do caráter qualiquantitativo do objeto, as IC e os temas foram agrupados em tabela única, juntamente com a frequência e o número relativo das E-Ch (tabela1).

As ideias mais compartilhadas entre os entrevistados em relação a cada questão norteadora e seus discursos foram descritos e discutidos com suporte da literatura científica.

\section{RESULTADOS E DISCUSSÃO}

Referente à participação dos alunos em atividades complementares institucionais, 38 $(73,1 \%)$ acadêmicos afirmaram ter participado de pesquisa científica, sendo que $32(61,5 \%)$ foram bolsistas, $11(21,1 \%)$ foram voluntários e $05(9,6 \%)$ participaram de ambas as formas (bolsista e voluntário). Quanto às atividades de extensão, $33(63,5 \%)$ afirmaram ter participado, sendo que apenas $06(11,5 \%)$ recebiam bolsa, 30 $(57,7 \%)$ exerciam a atividade sem fomento e 03 $(5,8 \%)$ alegaram ter participado de forma conjunta, voluntária e não voluntária. Em relação à monitoria, $42(80,8 \%)$ alunos tiveram contato com a atividade, sendo $09(17,3 \%)$ bolsistas, 36 $(69,2 \%)$ voluntários e $03(5,8 \%)$ exercendo a atividade nos dois formatos (gráfico 1).

Do total de participantes, 18 (34,6\%) forman- 
dos afirmaram ter vivenciado as três atividades analisadas, e 21 (40,4\%), vivenciaram a pesquisa científica e a extensão. Apenas um aluno afirmou não ter participado de nenhuma atividade complementar.

Ao serem questionados sobre a importância que o ensino, pesquisa e extensão tiveram em sua graduação, atribuindo um valor de 0 a 10, os alunos apontaram que o ensino foi o que obteve maior importância, seguido da extensão e da pesquisa científica (gráfico 2).

Das informações obtidas por meio das perguntas norteadoras abertas foram extraídos cinco temas e dezessete ideias centrais (quadro 1), sendo discutidas as ideias mais prevalentes.

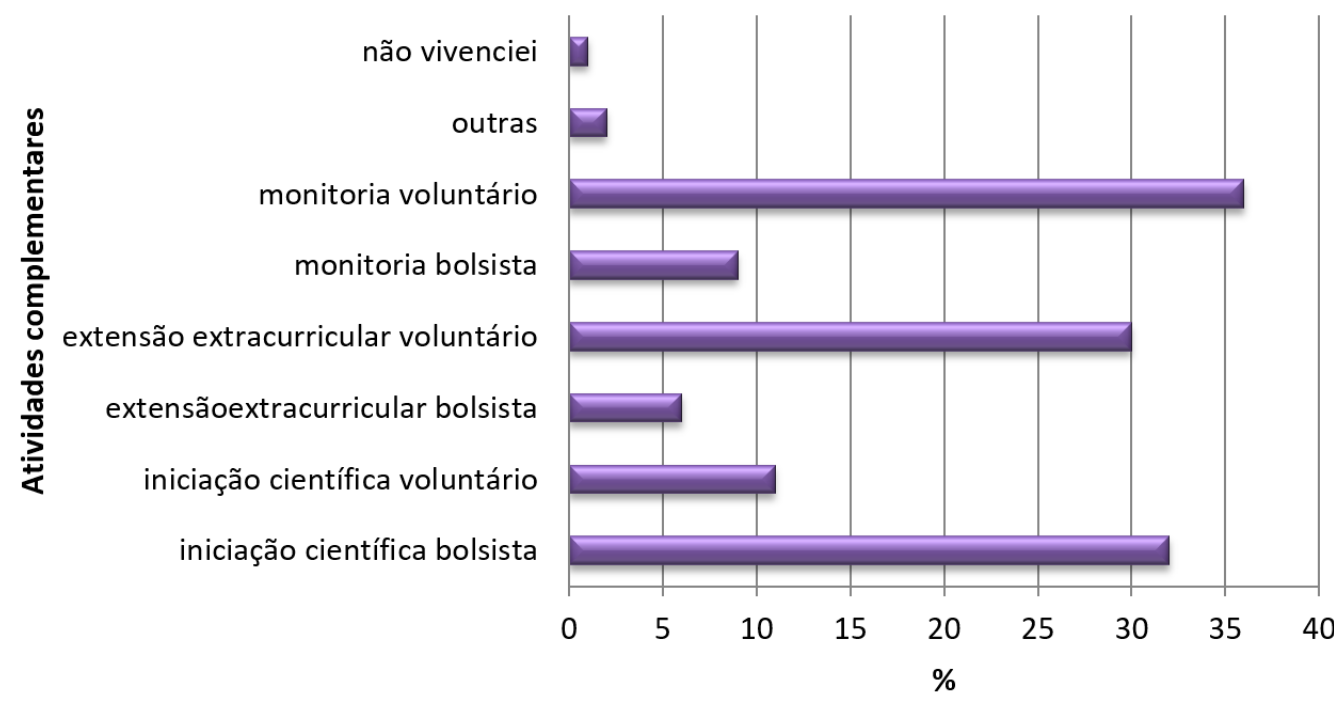

Gráfico 1. Percentual de atividades complementares institucionais vivenciadas pelos formandos investigados

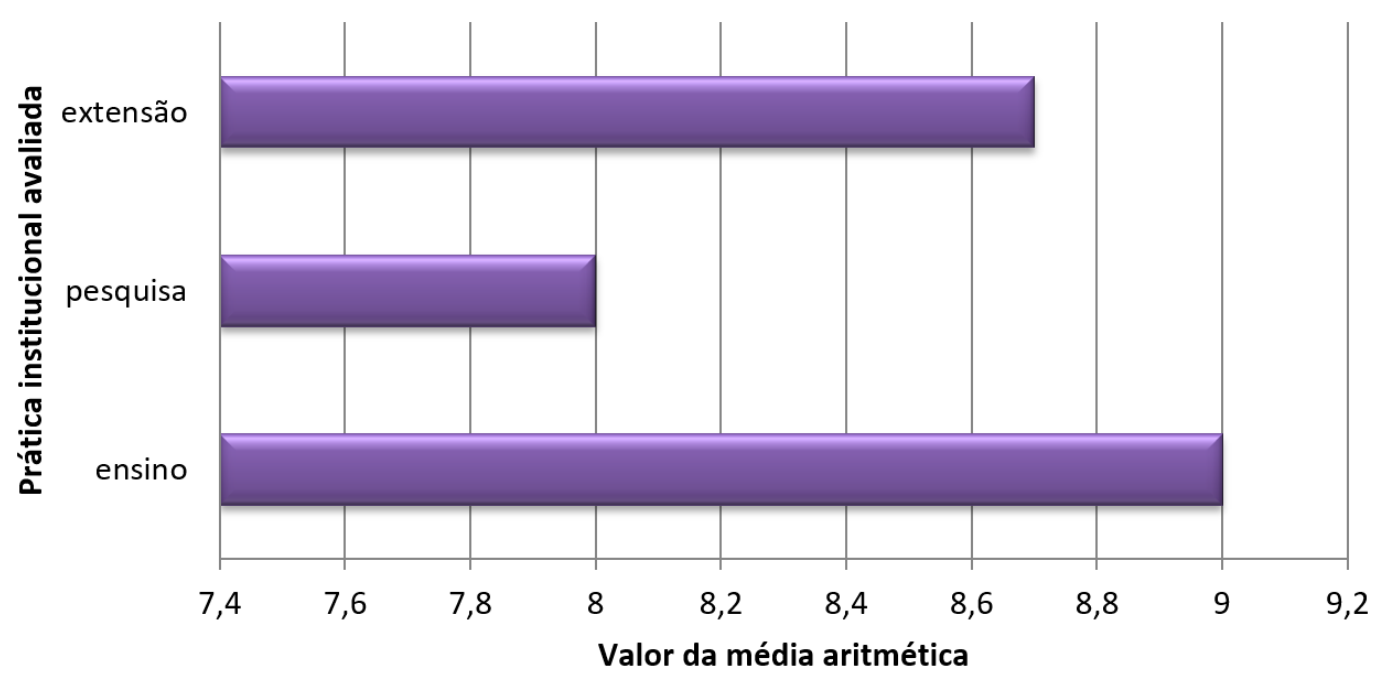

Gráfico 2. Média aritmética das notas atribuídas pelos pelos formandos investigados. 
Quadro 1. Proporção dos Discursos do Sujeito Coletivo segundo Ideias Centrais de sentidos semelhantes

\begin{tabular}{|c|c|c|c|}
\hline $\begin{array}{c}\text { Questões } \\
\text { norteadoras }\end{array}$ & $\begin{array}{c}\text { DSC Sínteses (agrupados por temas e } \\
\text { ideias centrais) }\end{array}$ & $\begin{array}{l}\text { Número de } \\
\text { E-Ch }\end{array}$ & $\%$ \\
\hline \multirow{13}{*}{$\begin{array}{c}\text { 1. Considerando o } \\
\text { ensino, a pesquisa e a } \\
\text { extensão, fale sobre o } \\
\text { que teve maior } \\
\text { importância em sua } \\
\text { formação acadêmica }\end{array}$} & $\begin{array}{l}\text { 1. Ensino, mola propulsora da formação } \\
\text { acadêmica? - } 2 \text { Discursos }\end{array}$ & 36 & 69,2 \\
\hline & A base de uma rede formadora educacional & 24 & 66,7 \\
\hline & $\begin{array}{l}\text { Fundamental sim, mas há de se enfrentar os } \\
\text { desafios }\end{array}$ & 12 & 33,3 \\
\hline & $\begin{array}{l}\text { 2. Pesquisa: excelência na formação } \\
\text { acadêmica - } 4 \text { Discursos }\end{array}$ & 36 & 69,2 \\
\hline & $\begin{array}{l}\text { Meio de aprofundamento e aquisição de } \\
\text { conhecimentos específicos }\end{array}$ & 11 & 30,5 \\
\hline & $\begin{array}{l}\text { Fomento para a qualificação do meio } \\
\text { acadêmico }\end{array}$ & 12 & 33,3 \\
\hline & A ausência de subsídio interno e externo & 6 & 16,7 \\
\hline & Discutindo sua aplicabilidade & 7 & 19,4 \\
\hline & $\begin{array}{l}\text { 3. Extensão: a valoração do que ainda é } \\
\text { pouco reconhecido - } 4 \text { Discursos }\end{array}$ & 36 & 69,2 \\
\hline & Oportunizando novas experiências & 16 & 44,4 \\
\hline & Valorizando o contato com a comunidade & 8 & 22,2 \\
\hline & O impacto na formação acadêmica & 6 & 16,7 \\
\hline & A ausência de subsídio interno e externo & 6 & 16,7 \\
\hline \multirow{5}{*}{$\begin{array}{l}\text { 2. Considerando o ensino, } \\
\text { a pesquisa e a extensão, } \\
\text { fale sobre o que tem maior } \\
\text { importância para a sua } \\
\text { universidade }\end{array}$} & $\begin{array}{l}\text { 4. Pilares da educação superior e a } \\
\text { valorização institucional - } 4 \text { Discursos }\end{array}$ & 40 & 76,9 \\
\hline & Importância superestimada à pesquisa & 16 & 40 \\
\hline & Importância à pesquisa e ao ensino & 4 & 10 \\
\hline & Importância somente ao ensino & 6 & 15 \\
\hline & $\begin{array}{l}\text { Importância igual ao ensino, pesquisa e } \\
\text { extensão }\end{array}$ & 14 & 35 \\
\hline \multirow{4}{*}{$\begin{array}{l}\text { 3. Para você, existe uma } \\
\text { correlação forte entre as } \\
\text { atividades de ensino, } \\
\text { pesquisa e extensão de sua } \\
\text { universidade? }\end{array}$} & $\begin{array}{l}\text { 5. Educação Superior construída sobre } \\
\text { alicerce triplo? - } 3 \text { Discursos }\end{array}$ & 31 & 59,6 \\
\hline & $\begin{array}{l}\text { Conexão fortalecida entre os pilares } \\
\text { educacionais }\end{array}$ & 19 & 61,2 \\
\hline & O isolamento da pesquisa e de seus interesses & 4 & 13 \\
\hline & $\begin{array}{l}\text { Reconhecendo a fragmentação no processo } \\
\text { educacional }\end{array}$ & 8 & 25,8 \\
\hline
\end{tabular}

Tema 1. Ensino, mola propulsora da formação acadêmica?

Ideia central: Base da rede formadora educacional.

DSC - O ensino é a base para tudo, onde ganhei experiência e conhecimento, e acho que deveria ser prioridade na faculdade, uma vez que desde a primeira aula o professor me enriqueceu em conhecimento e me colocou em outro nível, sendo fundamental para a minha formação acadêmica e para a minha futura profissão, trabalho e carreira [...]. Através dele (ensino) adquiri conhecimentos técnicos realmente necessários para a minha prática clínica [...] foi sim a base 


\section{fundamental da minha formação!}

A percepção exposta por grande parte dos alunos pesquisados confirma o papel central da aprendizagem atrelado ao pilar do 'ensino' e à figura do professor. Desde as origens das Instituições de Ensino Superior esta é a competência que de fato tem sido mais valorizada; não só por alunos, mas também por gestores de políticas educacionais, professores e sociedade $^{5}$. Historicamente, as IES se consolidaram justamente por exercer o papel de produtora e detentora de conhecimento ${ }^{16}$, atributo este fortemente arraigado às praticas de ensino.

A aula reprodutiva ou o instrucionismo é uma das grandes ameaças para a qualidade do ensino superior, dado que o aluno deve ser formado para conquistar a sua autonomia intelectual e moral ${ }^{5}$. Desta forma, o ensino deve ser composto por uma série de atividades que estimulem, facilitem e orientem progressivamente o processo de aprendizagem, estando os currículos articulados em torno de eixos orientadores de conteúdos significativos, tendo em vista as competências e habilidades que se pretende desenvolver.

Aspectos culturais e também a espécie de supervalorização dada ao professor no processo de ensino e aprendizagem sugerem influenciar os investigados, ainda que em contraposição a atuação do professor como regulador de situações múltiplas de aprendizagem ${ }^{10,17}$.

A sociedade moderna vem atuando por meio de movimentos dinâmicos de aprendizado, onde se torna fundamental a articulação do ensino formal com outros saberes ${ }^{10}$. Nesse sentido, a perspectiva curricular por competência requer que o estudante seja capaz de mobilizar múltiplos recursos (conhecimentos, habilidades e atitudes) para lidar em diferentes campos da vida social e individual ${ }^{10,17,18,19}$.

Estudiosos ${ }^{10,20}$ afirmam que o desafio para a formação é incorporar propostas de ensino que estejam inseridas no paradigma da complexidade, que discuta a realidade da globalização e absorva a construção da subjetividade do futuro profissional.

\section{Tema 2. Pesquisa: excelência na formação acadêmica.}

Ideia central: Fomento para a qualificação do meio acadêmico.

DSC - Penso que a pesquisa auxiliou mais minha formação [...]. A possibilidade de ter conhecimentos mais aprofundados em determinado assunto foi muito importante para mim, pois participando de pesquisas me familiarizei com o lado científico, aprendi mais com isso e tive exata noção de sua importância [...]. Possibilitou (pesquisa) que eu entendesse e enxergasse de outra forma o meio acadêmico, complementando o meu conhecimento fora da sala de aula. Enfim, ajudou na minha formação acadêmica completa e de mais qualidade.

A inserção do aluno de graduação em iniciativas de pesquisa representa um importante instrumento de aprimoramento de habilidades desejáveis para futuros profissionais, notada pelos acadêmicos entrevistados. Procedimentos simples, como técnicas de estudo e leitura, modos de análise, pensamento e escrita compatíveis com o rigor científico, além das etapas, fontes, métodos de abordagem $\mathrm{e}$ procedimento das pesquisas científicas, entre outros, devem enriquecer a jornada do estudante em seu percurso universitário ${ }^{12}$ uma vez que são capazes de permear o processo de competências de aprendizagem no ensino superior. Para o autor $^{21}$ a pesquisa universitária é a que melhor estabelece essas integrações entre o desempenho científico e técnico dos educandos, além de aprimorar sua vida profissional. 
As pesquisas devem ter a finalidade de ajudar na formação cidadã do futuro profissional, compondo a indissociabilidade entre os pilares da educação. Ainda, devem ser diversificadas nas instituições e ter fins produtivos para o mundo moderno, estando vinculadas as demandas da sociedade. Autores indicam que esses objetivos podem ser alcançados mantendo parcerias com entidades e organizações externas às $\mathrm{IES}^{22}$.

$\mathrm{Na}$ instituição de referência para este estudo, a introdução do estudante no universo da pesquisa ocorre principalmente por meio dos trabalhos de conclusão de curso e de projetos de pesquisadores isolados ou vinculados a um programa de iniciação científica. No entanto, para a consolidação qualitativa do aprendizado, a formação científica deveria ser de acesso universal e igualitário, incorporada de maneira plena na sociedade, o que não ocorre na maioria das instituições públicas no Brasil. As limitações no número de bolsas fazem da iniciação científica uma atividade seletiva, que beneficia poucos e discrimina muitos, aparentemente privilegiando os mais 'capacitados' $\mathrm{e}$ 'promissores'23.

A escassez de fomentos nas instituições públicas de ensino e a redução de editais de agências financiadoras é fato atual e relevante. Caso não haja políticas para a ampliação e democratização destes recursos, a inserção à pesquisa continuará ocorrendo de modo seletivo, beneficiando poucos ${ }^{24}$. Contudo, não só o financiamento é entrave para a expansão da pesquisa científica nas universidades; a falta de institucionalização também é uma dificuldade. Institucionalizar esta prática significa regulamentála, tratá-la como atividade de demanda curricular, seja obrigatória ou optativa, com regras de execução bem definidas, garantindo ao aluno tempo e espaço para praticá-la ${ }^{24}$.

Tema 3. Extensão: a valoração do que ainda é pouco reconhecido.

Ideia central: Oportunizando novas experiências.

DSC - Na extensão passei por experiências que nunca imaginei que um dia passaria e que me permitiram uma nova visão de mundo e experiências de formação acadêmica além da graduação, saindo do meu mundo particular [...]. Uma aprendizagem que o ensino não proporcionou, que não existe no currículo e que dentro da instituição não se pode ter. A extensão me ajudou a ter uma formação profissional de excelência, pela oportunidade de colocar em prática o conhecimento adquirido até então na teoria e também utilizá-lo na comunidade.

Ainda que as atividades de extensão universitária no Brasil e no mundo estruturalmente e filosoficamente não ocupem o mesmo espaço das práticas de ensino e pesquisa $^{13,25}$, os pesquisados desse estudo evidenciaram a sua importância formativa e, principalmente, cidadã. Do ponto de vista da formação da cidadania, não se aprende a ser cidadão apenas na teoria, mas na prática cotidiana $^{26}$. $\mathrm{O}$ exercício da cidadania exige o desenvolvimento de competências específicas, tais como a capacidade de criticar, de formar grupos e parcerias, de planejar, de propor e realizar ações em conjunto, competências essas que sobretudo a extensão pode ajudar a desenvolver ${ }^{7,13,27}$.

As ações promovidas pela extensão universitária objetivam o acesso da comunidade aos saberes científicos, filosóficos, culturais e tecnológicos, que confere um caráter dialógico à relação entre universidade e sociedade. Esse aspecto também foi considerado pelos estudantes como parte importante de seu processo formativo, quando acusam positivamente a interação de seus conhecimentos com a comunidade. A relação dos conhecimentos pode perfeitamente ser engendrada na atividade de 
extensão, que se achega ao conhecimento prático, assimilado culturalmente e desenvolvido para responder a demandas da vida em sociedade $^{28}$.

\section{Tema 4. Pilares da educação superior e a valorização institucional.}

Ideia central: Importância superestimada à pesquisa.

DSC - No meu curso a prioridade é muito para a pesquisa, sendo o ensino e a extensão o segundo plano [...], inclusive há muitos casos de disciplina que quem dá aula são os mestrandos e às vezes o ensino fica sim um pouco de lado [...]. Eu vejo que a pesquisa é mesmo supervalorizada porquê há uma dedicação maior dos professores e é onde existe também mais investimento.

Sabe-se que muitas instituições de ensino privilegiam atividades de pesquisa em virtude da captação de recursos financeiros de fontes públicas e privadas, do alargamento da visibilidade das ações desenvolvidas na instituição, e de uma espécie de status conferido a práticas científicas. Ainda, evidencia-se o valor desse tipo de atividade nos processos de ingresso e de promoção na carreira docente e pelo prestígio que confere aos docentes bemsucedidos nesse campo ${ }^{29}$.

De fato, o desenvolvimento da pesquisa dentro das universidades promove o vetor progresso $^{30}$. Alguns autores relatam que essa dedicação maior à pesquisa possui desdobramentos positivos, sendo esperado que os docentes propaguem seus conhecimentos adquiridos através da pesquisa na sala de aula, ministrando conteúdos mais elaborados e atualizados $^{31}$. No entanto, o que se tem observado, na maioria das vezes, são pesquisas docentes desconectadas das atividades de ensino $^{31}$ e, como também exposto pelos resultados do presente estudo, o afastamento do docente pesquisador das salas de aula da graduação $^{6,32}$.

Apesar do processo de exigência constante pelo desenvolvimento de pesquisa, essas pesquisas deveriam consolidar-se com a busca de problemáticas oriundas da realidade da sociedade e não exclusivamente do pesquisador, influenciando quantitativa e qualitativamente mudanças nas regiões onde as universidades estão inseridas ${ }^{12}$.

A possibilidade de contratação de professores equivalentes, cujas funções são voltadas especialmente ao ensino, também se torna um incentivo ao afastamento de professores titulares das práticas na graduação e à maior dedicação desses às atividades de pósgraduação $^{6}$, e consequentemente, à pesquisa.

\section{Tema 5. Educação Superior construída sobre alicerce triplo?}

Ideia central: Conexão fortalecida entre os pilares educacionais.

DSC - Existe sim. Eu acho que aqui a pesquisa alavanca o ensino e a extensão, contribuindo para integralizar a aprendizagem, dando ao aluno experiência, nova informação e prática [...] podemos fazer uso do ensino na pesquisa e nos projetos de extensão atuando profissionalmente de maneira mais adequada e usando as descobertas para aplicação fora do ambiente universitário.

Apesar do princípio da indissociabilidade na educação superior ter sido tratado inicialmente pela constituição brasileira vigente, a qual afirma que as universidades gozam de autonomia didático-científica, administrativa e de gestão, e deverão obedecer ao princípio de indissociabilidade entre ensino, pesquisa e extensão ${ }^{2,3}$ sob a ótica das atuais políticas públicas para o ensino superior, o cenário em 
relação ao implemento desse princípio tem se mostrado pouco promissor em vários estudos ${ }^{6,33}$.

As DCN sugerem a flexibilização na organização dos currículos pelas IES e a existência de uma base comum para os cursos da saúde. Além disso, as DCN igualmente sinalizam para a necessidade de maior interação entre ensino, serviço e comunidade ${ }^{3}$.

No entanto, alude-se que as DCN não estejam adequadamente sendo compreendidas por grande número de dirigentes, coordenadores, professores e alunos dos cursos de Odontologia, fato que pode estar retardando, prejudicando e dificultando as tentativas de revisão das estruturas curriculares das instituições de ensino e o próprio desenvolvimento dos cursos para a formação de um profissional compatível com a realidade das demandas sociais do país ${ }^{34}$.

A IES estudada nesse trabalho teve seu Projeto Didático-Pedagógico reformulado no ano de 2004, tendo como pressupostos fundamentais formar profissionais/cidadãos qualificados atuando na prevenção e tratamento das doenças bucais da população, baseada no conceito de saúde constitucionalmente estabelecido, bem como adequado às diretrizes do SUS. Seus docentes devem apresentar um perfil de facilitador e mediador do processo de ensino aprendizagem, participando e integralizando as atividades de ensino, pesquisa e extensão ${ }^{35}$. Cabe, no entanto, considerar que os resultados almejados pelos projetos de cada estrutura institucional podem ser diluídos, caso a interação entre essa estrutura e os objetivos propostos não estejam alinhados.

Neste viés teórico-metodológico, cabe aqui destacar a participação do Ministério da Saúde e do SUS na qualificação da formação acadêmica, ao instituir políticas indutoras para a transformação das práticas de formação, de atenção, de gestão, de formulação de políticas, de participação popular e de controle social no setor da saúde. A Educação Permanente em Saúde, o Programa Nacional de Reorientação da Formação Profissional em Saúde - Pró-Saúde, o Programa de Educação pelo Trabalho para a Saúde - PET-Saúde, os editais de pesquisa científica e tecnológica para qualificar o SUS e as próprias reformulações curriculares, com a inserção de alunos em diferentes cenários de prática desde os períodos iniciais, sinalizam avanços quanto à integração ensino-serviço e à própria formação acadêmica; não só no campo da odontologia, mas também, e principalmente, no âmbito da formação interprofissional ${ }^{34}$.

No presente trabalho, a percepção de que o ensino, a pesquisa e a extensão constituem eixo institucional fundamental e não compartimentado foi amplamente compartilhada pelos acadêmicos, apresentada sob duas hipóteses. A primeira é que, uma vez que a minoria dos acadêmicos pesquisados acusou ter tido acesso as três atividades complementares citadas, o que fica implícito é que a simples existência dessas atividades no curso parece influenciar a percepção acadêmica sobre o princípio da indissociabilidade. Este parece ser o viés mais comum das instituições, onde se tem o avanço da visibilidade da extensão, ao mesmo tempo em que esse espaço não corresponde a um incômodo ou mudanças para o ensino e a pesquisa, ou aos agentes universitários, particularmente docentes, que neles atuam ${ }^{16}$. A segunda hipótese é que, como a concretização deste princípio pressupõe a realização de processos coletivos de trabalho, com produção de saberes contextualizada e vinculação entre o planejamento, a execução e a avaliação das atividades de ensino, pesquisa e extensão, acredita-se que a percepção exposta possa também estar relacionada a uma mudança recente na atitude de alguns docentes da instituição pesquisada, os quais vêm assumindo a mediação e não o encerramento do processo de 
construção do conhecimento.

Esta postura educacional emergente é propósito das Diretrizes Curriculares Nacionais ${ }^{3}$ para os cursos de graduação em saúde garantindo a capacitação de profissionais com autonomia e discernimento para assegurar a integralidade da atenção e a qualidade e humanização do atendimento prestado aos indivíduos, famílias e comunidades ${ }^{9}$.

\section{CONSIDERAÇÕES FINAIS}

As expressões mostradas pela maioria dos acadêmicos analisados nesse estudo apontam para uma maior valorização do ensino, quando comparado a extensão e a pesquisa; para o entendimento de que a sua IES valoriza a pesquisa de forma ampliada e para a crença de que o ensino, a pesquisa e a extensão são eixos institucionais conexos na instituição.

Ressalta-se, porém, que apesar da valorização ampliada do ensino, por parte dos alunos; quantitativamente, observou-se uma diferença muito pequena entre os valores atribuídos as três atividades norteadoras, possibilitando a interpretação de que a pesquisa e a extensão estão alcançando espaço equivalente ao ensino quanto à sua importância na formação acadêmica. Ainda, que, sobre a valorização ampliada da pesquisa, por parte da instituição; a percepção acadêmica é negativa, afirmando o ensino fica em segundo plano, uma vez que as pesquisas são desconectas das atividades em sala de aula. E finalmente, a percepção da existência de conexão entre os princípios da indissociabilidade; apesar de somente um terço dos formandos afirmar ter vivenciado as três atividades analisadas.

Apesar dos resultados expostos, o desafio da consolidação de projetos integrados entre pesquisa, extensão e ensino nos cursos de formação graduada mantém-se presente nas universidades e, ainda hoje, é influenciado pela ideia de uma ciência tecnicista muito internalizada nas instituições e pouco voltada ao desenvolvimento humano e social. Acredita-se que quando as funções de pesquisa e extensão são adicionadas a dimensão do ensino, as universidades são induzidas a trabalhar com mais ênfase para a aplicação do conhecimento. Assim, descarta-se a valoração extremada dada ao ensino e à figura do docente no ensino superior como fonte privilegiada de acesso ao conhecimento.

Ressalta-se que a pesquisa, percebida nesse estudo como agente formativo de eleição institucional, quando isolada ou descontextualizada do ensino e da extensão possui pouca capacidade de desenvolvimento humano e profissional de forma integrada.

Sem dúvida, a indissociabilidade se relaciona intimamente à qualidade da produção e à socialização do conhecimento na educação superior, ao incorporar nos acadêmicos mecanismos de reflexão social e crítica, de emancipação teórica e prática. Assim, as IES brasileiras deparam-se com desafios comuns a serem superados, pois, se por um lado existem políticas que estimulam uma espécie de atitude reativa por parte da comunidade universitária, por outro, permanecem as dificuldades de institucionalização dessas novas práticas.

Nesse sentido, os resultados alcançados apresentam indicadores atuais baseados na percepção de acadêmicos concluintes de um curso da área da saúde e evidenciam o papel essencial das IES no aprimoramento de suas práticas de construção e compartilhamento do conhecimento e de sua função social.

\footnotetext{
ABSTRACT

Valuation of teaching practices, research and extension among Dental undergraduates

Given the importance of complementarity and interdependence among the pillars of higher
} 
education, the objective of this study is to know the value attributed to teaching, research and extension practices by Dental undergraduate students. A descriptive exploratory study was carried out with the use of a qualitative and quantitative methodology developed by all the graduates of the Dental Course of a public institution of higher education (base year: 2016) $(n=54)$. The seizure of the information of interest for this study occurred through a structured question and three open guiding questions. The quantitative results were presented through descriptive statistics, and qualitative data treated according to the Collective Subject Discourse analysis technique. Concerning the participation of students in complementary activities, $73,1 \%$ reported having participated in scientific research, 63,5\% in extension activities, and $80,8 \%$ in monitoring activities; and only $34,6 \%$ of the students reported experiencing the three activities analyzed. From the information obtained were extracted five themes and seventeen central ideas. The most shared ideas among the researched, about each theme extracted, point to a greater appreciation of teaching when compared to extension and research. Also, to the understanding that its higher education institution values research in an extended way and for the belief that teaching, research, and extension are related institutional axes in the institution. The results achieved show the need to improve the practices of knowledge construction and sharing in the analyzed institution.

Descriptors: Dentistry. Higher Education. Qualitative Research.

\section{REFERÊNCIAS}

1. Brasil. Constituição, 1988. Constituição da República Federativa do Brasil. Brasília: Senado Federal; 1988.

2. Ministério da Educação. Lei n 9.398 , de 20 de dezembro de 1996. Estabelece as diretrizes e bases da educação nacional. Diário Oficial da República Federativa do Brasil, Brasília, 23 dez 1996.

3. Brasil. Ministério da Educação. Diretrizes Curriculares Nacionais. [Acesso em 16 jun. 2017]. Disponível em: http://portal.mec.
gov.br/cne/arquivos/pdf/CES1300.pdf

4. Mizukami MGN. ENSINO: As abordagens do processo. São Paulo: EPU; 1986. Temas básicos da educação e ensino.

5. Bernheim CT, Chauí MS. Desafios da universidade na sociedade do conhecimento: cinco anos depois da conferência mundial sobre educação superior. Brasília: UNESCO; 2008.

6. Dias AMI. Discutindo caminhos para a indissociabilidade entre ensino, pesquisa e extensão. Rev Bras Docência Ensino Pesqui Educ Fís. 2009;1(1):37-52.

7. Magalhães HGD. Indissociabilidade entre pesquisa, ensino e extensão: tensões e desafios. ETD - Educ. 2007; 8(2):168-75.

8. Mazzilli S. Ensino, pesquisa e extensão: reconfiguração da universidade brasileira em tempos de redemocratização do Estado. RBPAE. 2011; 27(2):205-21.

9. Oliveira RG, Dias AL, Ferraz Júnior AM, Porto FR, Hespanhol FL, Silva RHA, et al. Problematização como método ativo de ensino-aprendizagem em um Curso de Odontologia. Rev ABENO 2015;15(2):74-81.

10. Zaroni FM, Strujak G, Magrin GL, Assunção LRS, Lima AAS, Fernandes A. Experiências de aprendizagem mais efetivas segundo acadêmicos de Odontologia. Rev. Abeno. 2015;15(3):80-7.

11. Mortimer EF. Construtivismo, mudança conceitual e ensino de ciências: para onde vamos? IENCI. 1996; 1(1):20-39.

12. Severino AJ. Metodologia do trabalho científico. São Paulo: Cortez; 2013.

13. Cardoso AC, Corralo DJ, Krahl M, Alves LP. O estimulo à prática da interdisciplinaridade e do multiprofissionalismo: a Extensão Universitária como uma estratégia para a educação interprofissional. Rev ABENO. 2015;15(2):12-9.

14. Jodelet D. As representações sociais. Rio de 
Janeiro: UERJ, 2001

15. Lefèvre F; Lefèvre AMC. O Discurso do Sujeito Coletivo: um novo enfoque em pesquisa qualitativa (Desdobramentos). Caxias do Sul: EDUCS; 2003.

16. Gonçalvez NG. Indissociabilidade entre Ensino, Pesquisa eExtensão: um princípio necessário. Perspec. 2015;33(3):1229-56.

17. Perrenoud P. Construir as competências desde a escola. Porto Alegre: Artmed; 1999.

18. Leonello VM, Oliveira MAC. Construindo competências para ação educativa da enfermeira na atenção básica. Rev Esc Enferm USP. 2007; 41:847-52.

19. Lima VV. Competência: distintas abordagens e implicações na formação de profissionais de saúde. Interface Comunic Saúde Educ. 2005; 9(17):369-79.

20. Scherer ZAP, Scherer EA. Identificação dos pilares da educação na disciplina integralidade no cuidado à saúde. Rev Esc Enferm USP. 2012;46(4): 985-93

21. Collins HM. Tacit knowledge, trust and the $Q$ of Sapphire. Soc Stud Sci. 2001;31(1): 71-85.

22. Fitzgerald HE, Bruns K, Sonka ST, Furco A, Swanson L. The centrality of engagement in Higher Education. J High Educ Outreach Engagem. 2002;16(3):7-25.

23. Massi L, Queiroz SL. Estudos sobre iniciação científica no Brasil: uma revisão. Cad Pesqui. 2010;40(139):173-97.

24. Tenório MP, Beraldi G. Iniciação científica no Brasil e nos cursos de Medicina. Rev Assoc Méd Bras. 2010;56(4):375-93.

25. Soares LR, Farias MCM, Farias MM. Ensino, pesquisa e extensão: histórico, abordagens, conceitos e considerações. Rev Ext. 2010; 9(1):11-8.

26. Magalhães HGD. A pedagogia do êxito: projetos de resultado. Petrópolis: Vozes; 2004.

27. Carneiro JA, Costa FMC, Lima CC, Otaviano MR, Fróes GJ. Unimontes
Solidária: Interação Comunitária e Prática Médica com a Extensão. Rev Bras Educ Méd. 2011;35(2):283-88.

28. Moita FMGSC, Andrade FCB. Ensinopesquisa-extensão: um exercício de indissociabilidade na pós-graduação. Rev Bras Educ. 2009; 14(41):269-393.

29. Santos LLCP. O observável e o imensurável na universidade do desempenho. Educ Rev. 2005;(42):201-18.

30. Fleck CF. A tríade ensino-pesquisa-extensão e os vetores para o desenvolvimento regional. G\&DR. 2011;7(3):270-98.

31. Santos LLCP. Dilemas e perspectivas na relação entre ensino e pesquisa. In: André M, Rosa DEG, Beillerot J, Soares M, Miranda MG, Lüdke M, et al. O papel da pesquisa na formação e na prática dos professores. $8 \mathrm{ed}$. Campinas: Papirus; 2008. p. 11-26.

32. Mazzilli S. Notas sobre indissociabilidade entre ensino-pesquisa-extensão. Educ Soc. 1996; (11):4-10.

33. Brasil. Ministério da Saúde. Ministério da Educação. A aderência dos cursos de graduação em enfermagem, medicina e odontologia às diretrizes curriculares nacionais / Ministério da Saúde, Ministério da Educação. - Brasília: Ministério da Saúde, 2006.

34. Finkler M, Caetano JC, Ramos FRS. Integração "ensino-serviço" no processo de mudança na formação profissional em Odontologia. Interface Comunic Saúde Educ. 2011;15(39):1053-70.

35. Universidade Estadual de Ponta Grossa. Departamento de Odontologia. Projeto Pedagógico. 2004.

Correspondência para:

Cristina Berger Fadel

e-mail: cbfadel@gmail.com

Rua Dr. Paula Xavier, 909

84010-270 Ponta Grossa/PR 